OPEN

SUBJECT AREAS:

ECOLOGY

MICROBIOLOGY

MICROBIAL ECOLOGY

Received

27 August 2013

Accepted

24 January 2014

Published

12 February 2014

Correspondence and requests for materials should be addressed to

S.W. (stephen.

whalan@scu.edu.au)

\section{Sponge larval settlement cues: the role of microbial biofilms in a warming ocean}

\author{
S. Whalan' \& N. S. Webster ${ }^{2}$
}

'Marine Ecology Research Centre, School of Environment Science \& Engineering, Southern Cross University, PO Box 157, Lismore, NSW, 2470, Australia, ${ }^{2}$ Australian Institute of Marine Science, PMB 3, Townsville, Qld, 4810, Australia.

Microbial biofilms play important roles in initiating settlement of marine invertebrate larvae. Given the importance of habitat selection by the motile larval phase, understanding settlement choices is critical if we are to successfully predict the population dynamics of sessile adults. Marine microbial biofilms show remarkable variability in community composition, often mediated by environmental conditions and biofilm age. To determine if biofilm communities were influenced by the time allowed to establish (age) and/ or seawater temperature, we manipulated experimental surfaces to firstly determine biofilm community composition and secondly test larval settlement responses for the abundant coral reef sponge Rhopaloeides odorabile. Microbial profiling of biofilms revealed different communities according to both age and temperature. Biofilm community composition, as a result of both elevated seawater temperature and biofilm age, contributed to settlement for sponge larvae with markedly higher numbers of larvae settling to biofilms developed over longer periods $(10 \mathrm{~d})$ and at temperatures $2-6^{\circ} \mathrm{C}$ above ambient.

T he mobile larval phase of sessile marine invertebrates is often critical to species distributions ${ }^{1}$. Complex behavior of marine invertebrate larvae has been established for many taxa and provides a compelling case that larval settlement is far from random ${ }^{2,3}$. Mechanical and chemical reception are used by invertebrate larvae to explore and selectively engage settlement sites ${ }^{4,5}$. Recruiting to optimal habitats is essential for sessile invertebrates, as initiation of settlement (metamorphosis) is often irreversible and successful recruitment is therefore largely linked to post-settlement environmental pressures ${ }^{6}$.

Microbial biofilms (biofilms) are implicated in the larval settlement of sessile invertebrates, a process established by pioneers in this field up to 7 decades $\mathrm{ago}^{7-9}$ and numerous others since ${ }^{2,10,11}$. Biofilms comprise communities of microorganisms, in addition to a matrix of extracellular polymeric compounds, which are thought to induce larval settlement ${ }^{12}$. Importantly, there are clear patterns of community succession in the composition of biofilms with bacteria being initial colonisers ${ }^{12-15}$. Development of biofilms over time involves the introduction of a diverse range of microorganisms ${ }^{12}$ under ambient environmental conditions. For marine invertebrate larval settlement, the age of biofilmed surfaces, and corresponding communities, contributes to settlement success ${ }^{16}$.

Increased sea surface temperatures (SST) and storm events (disturbances) associated with global climate change (GCC) are predicted to impact marine ecosystems ${ }^{17,18}$. Biofilm community composition can change when exposed to variable environmental conditions ${ }^{19-22}$ with potential concomitant effects on larval settlement ${ }^{23}$. As temperature can directly influence the development and composition of biofilms ${ }^{16}$, elevated SST could foreseeably have cascading consequences for the production of chemical cues that induce larval settlement. However, currently we have a very limited understanding of how larval settlement is influenced by the temperature biofilms are established at. GCC is predicted to influence biofilm community composition, not only through increased temperatures ${ }^{24}$, but also by creating open space (biofilm age) due to increased disturbance events. This study therefore aims to establish the effect of temperature and age on biofilm composition and determine how that corresponds to larval settlement for the coral reef sponge, Rhopaloeides odorabile.

\section{Results}

Larval settlement. Larval settlement was completed by 42 hours. Age of biofilm showed a significant main effect on settlement (Fig. 1: $\mathrm{F}={ }_{3,32}$ 13.42, $\mathrm{p}<0.01$ ) as did temperature (Fig. 1; $F={ }_{3,32} 5.46, \mathrm{p}<0.01$ ). However, a significant interaction between biofilm age and temperature drove larval settlement responses (Fig. $1 \& 2 ; F=9,32$ $2.30, \mathrm{p}=0.04)$. Of interest in the interaction was the notable trend at $28^{\circ} \mathrm{C}$ where marginal means remained relatively consistent over all levels of biofilm age. Settlement in treatments where biofilms were developed at $28^{\circ} \mathrm{C}$ for $10 \mathrm{~d}$ was lower in comparison to $30^{\circ} \mathrm{C}, 32^{\circ} \mathrm{C}$ and $34^{\circ} \mathrm{C}$ (Fig. 2). Indeed, the effect of temperature on settlement 


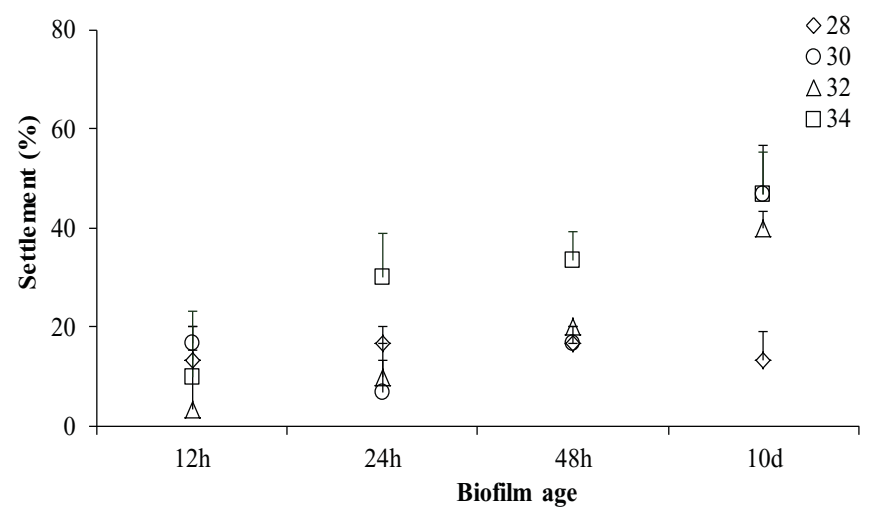

Figure $1 \mid$ Larval settlement (mean \pm s.e.) in response to biofilmed settlement surfaces established at different temperature and ages. Insert legend represents temperatures $\left({ }^{\circ} \mathrm{C}\right)$.

was different at every level of biofilm age for $28^{\circ} \mathrm{C}$, particularly from 24-48 $\mathrm{h}$ and from $48 \mathrm{~h}-10 \mathrm{~d}$. Moreover, the effect of increasing age of biofilm was reflected with an increasing effect of temperature, particularly from $30-34^{\circ} \mathrm{C}$.

Microbial biofilm community characterisation. MDS analysis produced an ordination which clearly separated two distinct clusters (A \& B-Fig. 3), where communities established at $10 \mathrm{~d}$ separated from newly established biofilms, irrespective of temperature. Within these two broad clusters there is evidence of gradients according to biofilm age and also temperature. For example, the cluster grouping $10 \mathrm{~d}$ biofilms (cluster A) also showed clear sub-groupings where biofilms at $34^{\circ} \mathrm{C}$ separated from biofilms developed at lower temperatures. While the patterns are less clear in cluster B, there was a weak gradient which distinguished $48 \mathrm{~h}$ biofilms according to temperature, where $34^{\circ} \mathrm{C}$ samples are grouped separately from the remainder of the $48 \mathrm{~h}$ temperature treatments.

\section{Discussion}

Biofilm induced larval settlement of the abundant Great Barrier Reef sponge Rhopaloeides odorabile was strongly influenced by both biofilm age and seawater temperature. In part, our results are consistent with evidence that biofilm age, alone, is an important cue for larval settlement in many taxa, with naïve biofilms being less inductive than more developed biofilms ${ }^{16}$. Biofilm age is strongly linked to microbial succession with pioneering biofilms generally supporting a low diversity of immediate colonisers and established biofilms comprising a higher diversity of bacteria and other single celled microorganisms ${ }^{14}$. Importantly, mature biofilms support a matrix of complex molecules and morphogenic signaling compounds which are thought to contribute to larval settlement in marine invertebrates ${ }^{2}$. For benthic sessile communities, where competition for space can influence Darwinian fitness, recognition of "open space" available for recruitment is critically important ${ }^{25}$. Open space, created by disturbance events ${ }^{26}$, results in bare surfaces with associated biofilm communities that can vary according to age of development and seawater temperature ${ }^{26,27}$.

Predicted increases in SST associated with $\mathrm{GCC}^{18}$ will likely influence biofilm development and composition and may also influence inter-kingdom signaling between microbes and invertebrate larvae. In this study, the most successful larval settlement occurred in response to biofilms developed for longer and at higher temperatures, with these biofilms supporting very different communities in comparison to naive biofilms (12-48 h) developed at lower temperatures $\left(28-32^{\circ} \mathrm{C}\right)$. The MDS ordination clearly distinguished $10 \mathrm{~d}$ old biofilm communities, with sub-groupings showing a separation gradient according to temperature. In contrast to the increased level

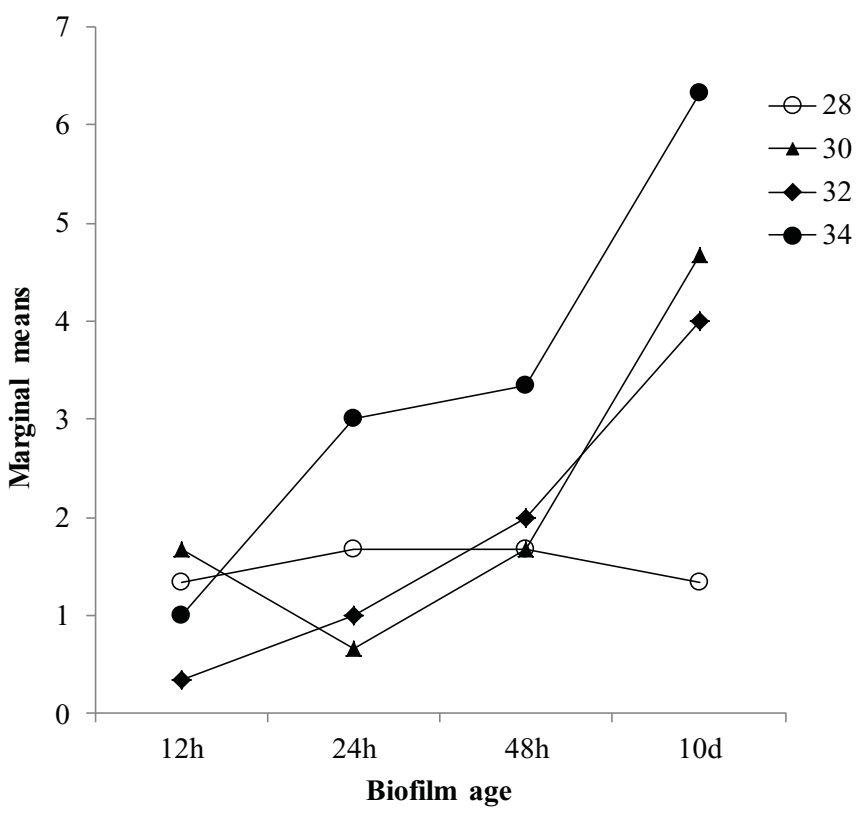

Figure 2 Interaction plot of estimated marginal means calculated for temperature at each level of biofilm age. Insert legend represents temperatures $\left({ }^{\circ} \mathrm{C}\right)$.

of sponge larval settlement, previous research has reported a shift in the microbial biofilms of crustose coralline algae (CCA) at elevated SST $\left(32^{\circ} \mathrm{C}\right)$ with an associated reduction in the ability of the CCA to induce settlement and metamorphosis of coral larvae ${ }^{24}$. These conflicting results indicate that responses may be taxa-specific which highlights the urgent need for further research to assess multi species responses within ecologically important invertebrate phyla.

To date, research aimed at determining the consequences of climate change has largely focused on processes such as organism physiology, with considerably less effort dedicated to population level effects such as larval recruitment. As demonstrated in this study differential microbial community development, via changing environmental conditions, can have consequences for larval settlement. In $R$. odorabile the thermal tolerance of adults is narrower than larvae. Larvae survive at temperatures up to $36^{\circ} \mathrm{C}$ whereas adults survive at temperatures of $32-33^{\circ} \mathrm{C}^{28-30}$. Both life phases engage distinct molecular pathways to deal with thermal stress ${ }^{31}$. Recognizing the distinction in thermal tolerance between each life history phase is critically important for populations as the motile larval phase has the capacity to disperse away from natal reefs ${ }^{1}$ and into habitats with different environmental conditions (including unique biofilm communities and corresponding larval settlement cues). The observed difference in thermal tolerance between the adult and larvae is likely due to epigenetic alterations that occur in response to different temperatures. Epigenetic forces such as DNA methylation and other mechanisms may alter the expression performance of individual genes in each life history stage and enable heritable stress response changes in the phenotype of each life history stage without altering the DNA sequence of the genome. Despite the thermal tolerance differences between life history stages in $R$. odorabile, and the findings in the present study, there are still unanswered questions surrounding adaption/acclimation of recruits to elevated temperatures predicted with climate change. Future research will therefore aim to test adaptation/acclimation of larvae, juveniles and adults to enable better predictions of how this species will respond to climate change. While a range of post-settlement processes (including climate) are important to overall recruitment ${ }^{32}$ the role biofilms play as an initial settlement cue for marine invertebrates, within a changing climate, could have significant cascading effects on population persistence ${ }^{33}$. 


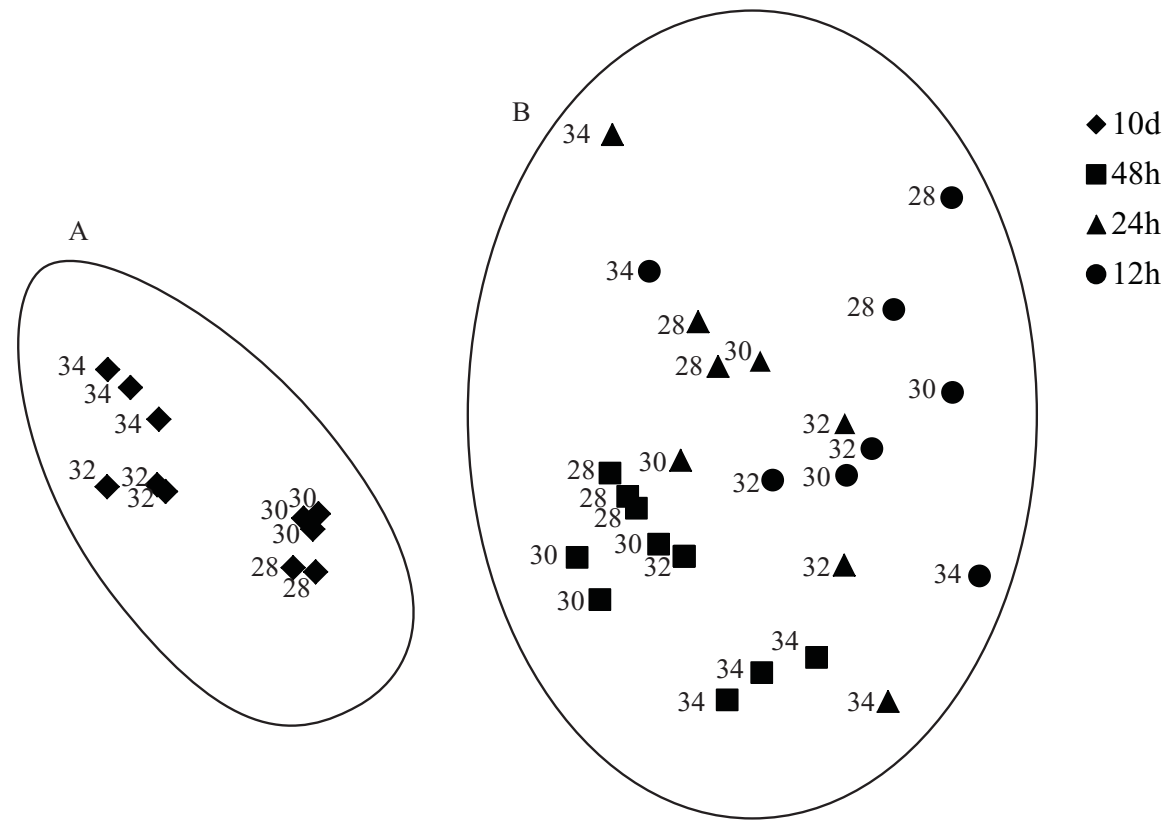

Figure 3 Multidimensional scaling ordination of microbial community compositions from settlement surfaces developed at different ages, and temperatures, as analysed by denaturing gradient gel electrophoresis.

\section{Methods}

Larval collection. Rhopaloeides odorabile is a common Great Barrier Reef sponge, which is gonochoristic and broods parenchymellae larvae with an annual spawning period occurring during January ${ }^{34}$. Ten whole female sponges were collected from Rib Reef, central Great Barrier Reef Australia $\left(18^{\circ} 29.51 \mathrm{~S}, 146^{\circ} 52.70 \mathrm{E}\right)$ and transported to the Australian Institute of Marine Science, Townsville, Australia (AIMS). Sponges were maintained in flow-through aquaria at AIMS which allowed the controlled collection of larvae over several hours during their afternoon release. Larvae were collected using larval traps, following established methods ${ }^{35}$.

Larval settlement. Biofilms were established in $70 \mathrm{ml}$ polystyrene specimen jars, which also formed the settlement surfaces, under flow-through sea water at AIMS. The seawater system at AIMS is unfiltered and represents coastal water similar to $R$. odorabile habitat. A factorial experiment to test the effects of age of biofilm and temperature under which biofilms developed was tested; biofilms were developed at $12 \mathrm{~h} 24 \mathrm{~h}, 48 \mathrm{~h}$ and $10 \mathrm{~d}$ at four temperatures: $28^{\circ} \mathrm{C}, 30^{\circ} \mathrm{C}, 32^{\circ} \mathrm{C}$ and $34^{\circ} \mathrm{C}(\mathrm{n}=3)$. In previous studies with $R$. odorabile and other closely related species, larval settlement has consistently reached levels ranging from $15-80 \%$ in biofilm treatments developed at approximately 10 days $s^{11,35,36}$ and this provided the rationale for establishing the maximum biofilm development period at 10 days in this study. The treatment at $28^{\circ} \mathrm{C}$ represents the approximate ambient sea temperature during spawning. Biofilms were developed in a staggered manner to allow larval settlement assays across all treatments to be run simultaneously.

Specimen jars with biofilm treatments were removed from tanks in which they were developed and each jar filled with $0.2 \mu \mathrm{m}$ filtered seawater. Ten larvae were gently pipetted into each experimental jar and monitored for metamorphosis. Settlement and metamorphosis of marine invertebrate larvae are terms that are often used interchangeably within the literature but reflect different life stages ${ }^{2}$.

Metamorphosis represents a life stage where the larva undergoes clear changes that begin to reflect juvenile morphology $y^{2}$. Because this is the first stage toward recruitment only larvae that had undergone clear metamorphosis were scored.

Metamorphosis of R. odorabile larvae is therefore defined as attachment to the surface and flattening of the entire body to form a disc like morphology, the centre showing the remnants of the posterior larval pole ${ }^{35}$. We use the term settlement throughout for ease of readership.

Microbial biofilm community characterisation. Biofilm community composition was analysed using Denaturing Gradient Gel Electrophoresis (DGGE). Biofilmed surfaces were sampled by thoroughly swabbing the surfaces of specimen jars using sterile cotton swabs which were subsequently frozen in liquid nitrogen, pending DNA extraction. DNA was extracted from biofilm samples (cotton swabs) using the Power Plant DNA Isolation kit, MoBio Laboratories (Carlsbad, CA) according to the manufacturer's protocol. The $16 \mathrm{~S}$ rRNA gene from each biofilm sample was amplified by PCR with primers $1055 \mathrm{f}$ and $1406 \mathrm{r}^{37}$ with the reverse primer incorporating the GC clamp $^{38}$. PCR reactions were performed as described by ${ }^{37}$. Products from triplicate PCR reactions were combined and $15 \mu \mathrm{l}$ applied to duplicate $8 \% \mathrm{w} / \mathrm{v}$ polyacrylamide $(37.5: 1)$ gels containing a $50-70 \%$ denaturing gradient of formamide and urea. Gels were electrophoresed at $60^{\circ} \mathrm{C}$ for $17 \mathrm{~h}$ in $1 \times \mathrm{TAE}$ buffer at $50 \mathrm{~V}$ using the Ingeny
D-Code system. Gels were stained with $1 \times$ Sybr Gold for 30 min, visualised under UV illumination and photographed.

Data analysis. Larval metamorphosis was analysed by 2 factor Analysis of Variance (ANOVA) using larval metamorphosis scored at the completion of the experiment as the response variable, and age of biofilm development and temperature of biofilm development as fixed factors. Analysis of the biofilm community composition relied on 16S rRNA gene fingerprints of the DGGE gels which were manually assessed and a matrix constructed using the presence (1) or absence (0) of a band in each sample. Non-metric Multidimensional Scaling (MDS) ordination was then applied to this data using Primer+PERMANOVA software package (PRIMER-E Ltd) to visually assess the influence of time and temperature on biofilm community composition. MDS patterns were complimented by cluster analysis (using group average on a Euclidean distance matrix) within the Primer+PERMANOVA package to help establish differences among the treatments.

1. Whalan, S. et al. Low genetic variability within and among populations of the brooding sponge Rhopaloeides odorabile on the central Great Barrier Reef. Aquat. Biol 3, 111-119doi:10.3354/ab00066 (2008).

2. Hadfield, M. G. Biofilms and marine invertebrate larvae: What bacteria produce that larvae use to choose settlement sites. Ann. Rev. Mar. Sci. 3, 453-470, doi:10.1146/annrev-marine-120709-142753 (2011).

3. Hay, M. E. Marine chemical ecology: What's known and what's next? J.f Exp. Mar. Biol. Ecol. 200, 103-134, doi:10.1016/50022-0981(96)02659-7 (1996).

4. Whalan, S., Webster, N. S. \& Negri, A. P. Crustose coralline algae and a cnidarian neuropeptide trigger larval settlement in two coral reef sponges. PLoS ONE 7, doi:10.1371/journal.pone.0030386 (2012).

5. Maruzzo, D., Conlan, S., Aldred, N., Clare, A. S. \& Hoeg J. T. Video observation of surface exploration in cyprids of Balanus amphitrite: the movements of antennular sensory setae. Biofouling 27, 225-239, doi:10.1080/ 08927014.2011.555534 (2011).

6. Marshall, D. J., Monro, K., Bode, M., Keough, M. J. \& Swearer, S. Phenotypeenvironment mismatches reduce connectivity in the sea. Ecol. Letters 13, 128-140, doi:10.1111/j.1461-0248.2009.01408.x (2010).

7. Miller, M. A., Rapean, J. C. \& Whedon, W. F. The role of slime film on the attachment of fouling organisms. Biol. Bull. 94, 143-157 (1948).

8. ZoBell, C. E. \& Allen, E. C. The significance of marine bacteria in the fouling of submerged surfaces. J. Bacteriol. 29, 239-251 (1935).

9. Crisp, D. J. \& Ryland, J. S. Influence of filming and of surface texture on the settlement of marine organisms. Nature 185, 119, doi:10.1038/185119a0 (1960).

10. Webster, N. S. et al. Metamorphosis of a scleractinian coral in response to microbial biofilms. Appl.Environ. Microbiol. 70, 1213-1221, doi:10.1128/ aem.70.2.1213-1221.2004 (2004).

11. Wahab, M. A. A., de Nys, R. \& Whalan, S. Larval behaviour and settlement cues of a brooding coral reef sponge. Coral Reefs 30, 451-460, doi:10.1007/s00338-0110727-5 (2011).

12. Qian, P. Y., Lau, S. C. K., Dahms, H. U., Dobretsov, S. \& Harder, T. Marine biofilms as mediators of colonization by marine macroorganisms: Implications 
for antifouling and aquaculture. Mar.Biotech. 9, 399-410, doi:10.1007/s10126007-9001-9 (2007)

13. Bourne, D. G., Hoj, L., Webster, N. S., Swan, J. \& Hall, M. Biofilm development within a larval rearing tank of the tropical rock lobster, Panulirus ornatus. Aquaculture 260, 27-38, doi:10.1016/j.aquaculture.2006.06.023 (2006).

14. Lam, C., Harder, T. \& Qian, P. Y. Growth conditions of benthic diatoms affect quality and quantity of extracellular polymeric larval settlement cues. Mar. Ecol.Prog.Ser. 294, 109-116, doi:10.3354/meps294109 (2005).

15. Webster, N. S. \& Negri, A. P. Site-specific variation in Antarctic marine biofilms established on artificial surfaces. Enviro. Microbiol. 8, 1177-1190, doi:10.1111/ j.1462-2920.2006.01007.x (2006).

16. Keough, M. J. \& Raimondi, P. T. Responses of settling invertebrate larvae to bioorganic films: Effects of large-scale variation in films. J. Exp.Mar.Biol. Ecol. 207, 59-78, doi:10.1016/5022-0981(96)02632-9 (1996).

17. Webster, P. J., Holland, G. J., Curry, J. A. \& H-R, C. Changes in Tropical Cyclone Number, Duration, and Intensity in a Warming Environment. Science 309, 1844-1846, doi:10.1126/science.1116448 (2005).

18. Meehl, G. A. et al. IPCC Climate Change 2007: The physical science basis. Contribution of working group I to the fourth assessment report of the intergovernmental panel on climate change., 996 (Cambridge University Press, Cambridge, UK., 2007).

19. Chung, H. C. et al. Bacterial community succession and chemical profiles of subtidal biofilms in relation to larval settlement of the polychaete Hydroides elegans. ISME J. 4, 817-828, doi:10.1038/ismej.2009.157 (2010).

20. Nagarkar, S. \& Williams, G. A. Spatial and temporal variation of cyanobacteriadominated epilithic communities on a tropical shore in Hong Kong. Phycologia 38, 385-393, doi:10.2216/i0031-8884-38-5-385.1 (1999).

21. Witt, V., Wild, C., Anthony, K. R. N., Diaz-Pulido, G. \& Uthicke, S. Effects of ocean acidification on microbial community composition of, and oxygen fluxes through, biofilms from the Great Barrier Reef. Environ. Microb. 13, 2976-2989, doi:10.1111/j.1462-2920.2011.02571.x (2011).

22. Lau, S. C. K., Thiyagarajan, V., Cheung, S. C. K. \& Qian, P. Y. Roles of bacterial community composition in biofilms as a mediator for larval settlement of three marine invertebrates. Aquat.Microb. Ecol. 38, 41-51, doi:10.3354/ame038041 (2005).

23. Qian, P. Y., Thiyagarajan, V., Lau, S. C. K. \& Cheung, S. C. K. Relationship between bacterial community profile in biofilm and attachment of the acorn barnacle Balanus amphrite. Aquat.Microb. Ecol. 33, 225-237, doi:10.3254/ame033225 (2003).

24. Webster, N. S., Soo, R., Cobb, R. \& Negri, A. P. Elevated seawater temperature causes a microbial shift on crustose coralline algae with implications for the recruitment of coral larvae. ISME J. 5, 759-770, doi:10.1038/ismej.2010.152 (2011).

25. Chadwick, N. \& Morrow, K. in Coral Reefs: an ecosystem in transition (eds Dubinsky Z \& Stambler N) 347-371 (Springer, 2011).

26. Keough, M. J. \& Raimondi, P. T. Responses of settling invertebrate larvae to bioorganic films - effects of different types of films. J. Exp.Mar.Biol.Ecol. 185, 235-253, doi:10.1016/00222-0981(94)00154-6 (1995).

27. Diaz Villanueva, V., Font, J., Schwartz, T. \& Romani, A. M. Biofilm formation at warming temperature: acceleration of microbial colonization and microbial interactive effects. Biofouling 27, 59-71, doi:10.1080/08927014.2010.538841 (2011)

28. Whalan, S., Ettinger-Epstein, P. \& de Nys, R. The effect of temperature on larval pre-settlement duration and metamorphosis for the sponge, Rhopaloeides odorabile. Coral Reefs 27, 783-786, doi:10.1007/s00338-008-0400-9 (2008).
29. Webster, N. S., Botte, E. S., Soo, R. M. \& Whalan, S. The larval sponge holobiont exhibits high thermal tolerance. Environ. Microb.Reports 3, 756-762, doi:10.1111/ j.1758-2229.2011.00296.x (2011).

30. Fan, L., Liu, M., Simister, R., Webster, N. S. \& Thomas, T. Marine microbial symbiosis heats up: Loss of interactions in a sponge holobiont under thermal stress. ISME J.l 7, 991-1002, doi:10.1038/ismej.2012.165 (2013).

31. Webster, N. et al. A complex life cycle in a warming planet: gene expression in thermally stressed sponges. Mol. Ecol. 22, 1854-1868, doi: $10.1111 /$ mec.12213 (2013).

32. Cowen, R. K. \& Sponaugle, S. Larval dispersal and marine population connectivity. Ann. Rev.Mar.Sci. 1, 443-466, doi:10.1146/ annurev.marine.010908.163757 (2009).

33. Battin, T. J., Kaplan, L. A., Newbold, J. D. \& Hansen, C. M. E. Contributions of microbial biofilms to ecosystem processes in stream mesocosms. Nature $\mathbf{4 2 6}$ 439-442, doi:10.1038/nature02152 (2003).

34. Whalan, S., Battershill, C. \& de Nys, R. Variability in reproductive output across a water quality gradient for a tropical marine sponge. Mar.Biol. 153, 163-169, doi:10.1007/s00227-007-0792-z (2007).

35. Whalan, S., Ettinger-Epstein, P., Battershill, C. \& de Nys, R. Larval vertical migration and hierarchical selectivity of settlement in a brooding marine sponge. Mar. Ecol.Prog.Ser. 368, 145-154, doi:10.3354/meps07573 (2008).

36. Ettinger-Epstein, P., Whalan, S., Battershill, C. N. \& de Nys, R. A hierarchy of settlement cues influences larval behaviour in a coral reef sponge. Mar.Ecol.Prog.Ser. 365, 103-113, doi:10.3354/meps07503 (2008).

37. Ferris, M. J., Muyzer, G. \& Ward, D. M. Denaturing gradient gel electrophoresis profiles of $16 \mathrm{~S}$ rRNA-defined populations inhabiting a hot spring microbial mat community. App. Environ. Microb. 62, 340-346 (1996).

38. Muyzer, G., de Waal, E. C. \& Uitterlinden, A. G. Profiling of complex microbia populations by denaturing gradient gel electrophoresis analysis of polymerase chain reaction-amplified genes coding for $16 \mathrm{~S}$ rRNA. App.Environ. Microb. 59, 695-700 (1993).

\section{Acknowledgments}

Funding to SW was provided through the Australian Research Council (ARC) (LP990664) and to NSW through an ARC Future Fellowship (FT120100480).

\section{Author contributions}

S.W. and N.S.W. conceived the study, undertook experiments and analysed the data. S.W. wrote the main manuscript text, and both authors reviewed the manuscript.

\section{Additional information}

Competing financial interests: The authors declare no competing financial interests.

How to cite this article: Whalan, S. \& Webster, N.S. Sponge larval settlement cues: the role of microbial biofilms in a warming ocean. Sci. Rep. 4, 4072; DOI:10.1038/srep04072 (2014).

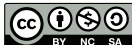

This work is licensed under a Creative Commons AttributionNonCommercial-ShareAlike 3.0 Unported license. To view a copy of this license, visit http://creativecommons.org/licenses/by-nc-sa/3.0 


\section{SCIENTIFIC \\ REP RTS}

DOI: 10.1038/srep05141

SUBJECT AREAS: ERRATUM: Sponge larval settlement cues: the role of microbial biofilms in a ECOLOGY warming ocean

MICROBIOLOGY

MICROBIAL ECOLOGY

\section{SCIENTIFIC REPORTS:}

$4: 4072$

DOI: 10.1038/srep04072

(2014)

Published:

12 February 2014

Updated:

19 November 2014

\section{S. Whalan \& N. S. Webster}

There is a typographical error in Figure 2 of this Article. "Marginal means" should read "Settlement (marginal means)". The correct Figure 2 appears below as Figure 1.

In addition reference 11 should read:

Abdul Wahab, M. A., de Nys, R. \& Whalan, S. Larval behaviour and settlement cues of a brooding coral reef sponge. Coral Reefs 30, 451-460, doi:10.1007/s00338-011-0727-5 (2011).

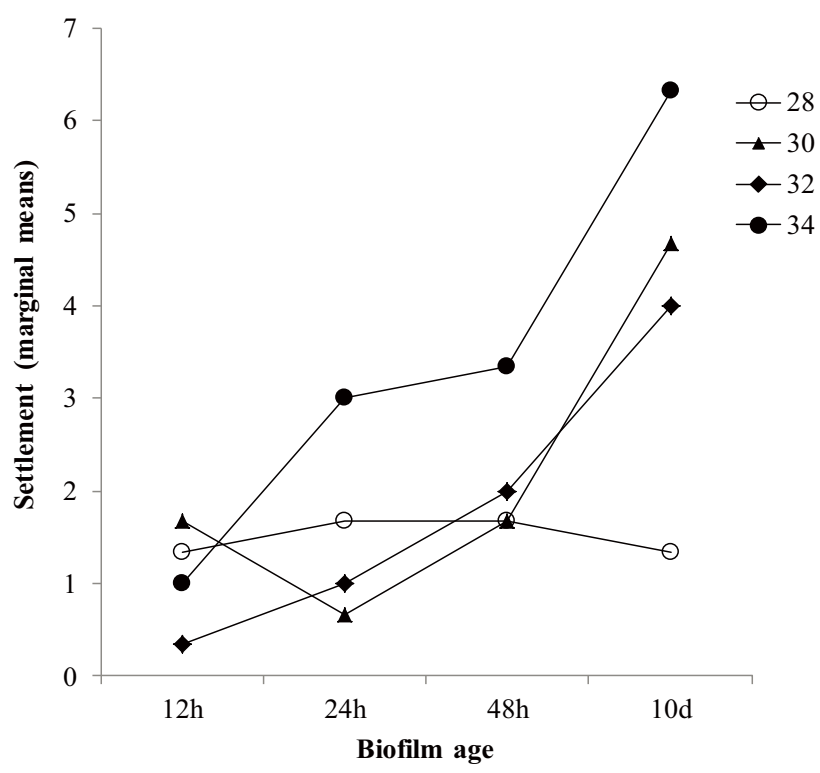

Figure 1 